OPEN ACCESS

Edited by:

Paul Manger,

University of the Witwatersrand,

South Africa

Reviewed by:

Adhil Bhagwandin,

University of Cape Town, South Africa

Ayanda Ngwenya,

University of the Witwatersrand,

South Africa

Jean-Pierre Hornung,

Université de Lausanne, Switzerland

${ }^{*}$ Correspondence:

Tomoko Soga

tomoko.soga@monash.edu

Received: 10 September 2018 Accepted: 21 November 2018

Published: 06 December 2018

Citation:

Cham KL, Soga T and Parhar IS (2018) Expression of RING Finger

Protein 38 in Serotonergic Neurons in the Brain of Nile Tilapia,

Oreochromis niloticus.

Front. Neuroanat. 12:109.

doi: 10.3389/fnana.2018.00109

\section{Expression of RING Finger Protein 38 in Serotonergic Neurons in the Brain of Nile Tilapia, Oreochromis niloticus}

\author{
Kai Lin Cham, Tomoko Soga* and Ishwar S. Parhar \\ Brain Research Institute, School of Medicine and Health Sciences, Monash University Malaysia, Bandar Sunway, Malaysia
}

Serotonin (5-hydroxytryptamine, 5-HT) is one of the major neurotransmitters, modulating diverse behaviours and physiological functions. Really interesting new gene (RING) finger protein 38 (RNF38) is an E3 ubiquitin ligase whose function remains unclear. A recent study has shown a possible regulatory relationship between RNF38 and the 5-HT system. Therefore, to gain insight into the role of RNF38 in the central $5-\mathrm{HT}$ system, we identified the neuroanatomical location of $5-\mathrm{HT}$ positive cells and investigated the relationship between RNF38 and the 5-HT system in the brain of the Nile tilapia, Oreochromis niloticus. Immunocytochemistry revealed three neuronal populations of 5-HT in the brain of tilapia; the paraventricular organ (PVO), the dorsal and ventral periventricular pretectal nuclei (PPd and PPv), and, the superior and inferior raphe (SR and IR). The 5-HT neuronal number was highest in the raphe (90.4 in SR, 284.6 in IR), followed by the pretectal area (22.3 in PPd, 209.8 in PPv). Doublelabel immunocytochemistry showed that the majority of $5-\mathrm{HT}$ neurons express RNF38 nuclear proteins (66.5\% in PPd; 77.9\% in PPv; 35.7\% in SR; 49.1\% in IR). These findings suggest that RNF38 could be involved in E3 ubiquitination in the central 5-HT system.

Keywords: E3 ubiquitin ligase, periventricular pretectal nuclei, raphe, brain, tilapia, teleost

\section{INTRODUCTION}

The monoamine neurotransmitter serotonin (5-hydroxytryptamine, 5-HT) is one of the major neurotransmitters, modulating diverse behavioural and physiological functions such as mood, fear, aggression, appetite, sleep, memory and reproduction (Jacobs and Azmitia, 1992; Lucki, 1998; Charnay and Léger, 2010; Lillesaar, 2011). Furthermore, 5-HT has also been shown to regulate developmental processes such as cell migration, cell proliferation, neuronal differentiation, neurogenesis, synaptogenesis, and apoptosis (Azmitia, 2001; Gaspar et al., 2003; Cote et al., 2007; Pérez et al., 2013). The wide variety of 5-HT-mediated functions indicate an important role in the central nervous system, and dysfunction in the 5-HT function is often associated with several neuropathologic conditions such as anxiety, schizophrenia and depression (Charney et al., 1987; Owens and Nemeroff, 1994; Breier, 1995). Despite concerted efforts to characterise 5HT's multiple roles, the target brain regions responsible for its capacity to modulate behavioural and neuroendocrine responses, and the underlying mechanisms involved in these neurological disorders, remain poorly understood.

The central 5-HT system is well characterised in the brains of vertebrates. In all vertebrates studied, such as mammals (Dahlström and Fuxe, 1964; Steinbusch, 1981; Charnay and Léger, 2010), amphibians (Ueda et al., 1984; Clairambault et al., 1994), reptiles (Wolters et al., 1985; 
Ayala-Guerrero et al., 1991), birds (Challet et al., 1996) and fish (Meek and Joosten, 1989; Kaslin and Panula, 2001; Loveland et al., 2014), the main population of the 5-HT-containing neurons is restricted in the raphe nucleus in the hindbrain. These raphe 5-HT neurons can be further classified into the superior raphe (SR) and the inferior raphe (IR) subnuclei based on their neuroanatomical locations, projection areas, electrophysiological properties, molecular architectures and functional properties (Kirby et al., 2003; Abrams et al., 2004; Beck et al., 2004; Wylie et al., 2010; Gaspar and Lillesaar, 2012; Loveland et al., 2014). Studies have shown that 5-HT neurons in the SR give rise to ascending pathways that innervate most of the brain areas, whereas the IR provides descending pathways to the brain stem and spinal cord. In fish, 5-HT neurons are also found in the nucleus of the paraventricular organ (PVO) and periventricular pretectal nuclei (PP) (Kaslin and Panula, 2001; Loveland et al., 2014).

A recent study has shown that really interesting new gene (RING) finger protein 38 (RNF38) is modulated by the 5-HT system (Moriya et al., 2015). RNF38 is a member of the RING finger family, characterised by a RING domain and a zincbinding motif. It possesses a RING-H2 domain $\left(\mathrm{C}_{3} \mathrm{H}_{2} \mathrm{C}_{2}\right)$ and a coiled-coil domain, suggesting that it is involved in proteinprotein/DNA interactions (Eisenberg et al., 2002; Moriya et al., 2015). The function of RNF38, to date, remains unclear. However, RING finger proteins have been shown to regulate various cellular processes such as the cell cycle (Gmachl et al., 2000; Jia et al., 2009), cell signalling (Vallabhapurapu et al., 2008), DNA repair (Gowen et al., 1998; Ulrich and Jentsch, 2000), vesicular trafficking (Srivastava et al., 2000; Matsuda et al., 2001), tumour suppression (Roperch et al., 1999; Sanada et al., 2009) and apoptosis ( $\mathrm{Hu}$ and Yang, 2003; Kojima et al., 2005). Rnf38 mRNA is found in the brain, spleen, liver, heart, testis, and placenta (Eisenberg et al., 2002), and its protein is a nuclear protein capable of mediating ubiquitination of the p53 tumour-suppressor protein (Sheren and Kassenbrock, 2013), thus acting as an E3 ubiquitin ligase. In the brain, rnf38 mRNA and its protein are widely distributed, including the telencephalon, preoptic area, optic tectum, hypothalamus, cerebellum and the hindbrain in male tilapia (Cham et al., 2017). Furthermore, the same study showed that RNF38 protein is absent in astroglial cells, but is expressed in the nucleus of neuronal cells (Cham et al., 2017), suggesting that RNF38 may be involved in neuronal functions by interacting with various proteins. RNF38 is also linked to cancerous diseases and ageing (Fu et al., 2006; Nacheva et al., 2010; Sato et al., 2013; Xiong et al., 2018). For example, $r n f 38 \mathrm{mRNA}$ and protein levels are upregulated in non-small cell lung cancer (NSCLC), which in turn increases proliferation and the metastatic capacity of the cells (Xiong et al., 2018), whereas rnf38 mRNA is increased in the hypothalamus during ageing ( $\mathrm{Fu}$ et al., 2006).

The regulatory relationship between RNF38 and the 5-HT system remains to be elucidated. As an E3 ubiquitin ligase, RNF38 maintains cellular function by controlling the protein homeostasis within neurons via the ubiquitin proteasome system (UPS). To understand the relationship between RNF38 and 5-HT, we localised the distribution of RNF38 and the 5-HT neurons in the brain of Oreochromis niloticus using double-labelling immunocytochemistry.

\section{MATERIALS AND METHODS}

\section{Animals}

Sexually matured male Nile tilapia (O. niloticus) (6 months old) were maintained under a controlled natural photo regime (14-h light; 10-h dark cycle) in standard fish tanks (size: $450 \times 295 \times 300 \mathrm{~mm}$ ) equipped with a continuous supply of aerated freshwater at $28 \pm 0.5^{\circ} \mathrm{C}$. The fish were fed twice per day with commercial cichlid pellets (Star Feedmills, Selangor, Malaysia). All experimental procedures were performed under the guidelines of Monash University Animal Ethics Committee, AEC (MARP/2015/109).

\section{Localisation of 5-HT Neurons in the Brain Brain Tissue Preparation for Immunocytochemistry}

Male tilapia $(n=2)$ were anaesthetised using a $0.02 \%$ benzocaine solution (Sigma, St. Louis, MO, United States). The fish were then decapitated and the brains harvested. Gonads were examined macroscopically to confirm that the fish were sexually matured. The whole brain samples were then fixed in $4 \%$ paraformaldehyde in a $0.1 \mathrm{M}$ phosphate buffer $\left(\mathrm{pH} 7.3\right.$ ) for $6 \mathrm{~h}$ at $4^{\circ} \mathrm{C}$ followed by cryoprotection in $20 \%$ sucrose in a $0.1 \mathrm{M}$ phosphate buffer $(\mathrm{pH}$ 7.3). The cryoprotected whole brain samples were then embedded in frozen section compound (Leica, Wetzlar, Germany) and sectioned coronally at $15 \mu \mathrm{m}$ using a cryostat (Leica CM1860). The sections were mounted onto silane-coated glass slides (Muto Pure Chemicals, Tokyo, Japan) and stored at $-80^{\circ} \mathrm{C}$ until use for immunocytochemistry.

\section{Immunocytochemistry}

Sections were rehydrated in phosphate-buffered saline and a blocking solution containing 2\% normal goat serum and $0.5 \%$ Triton-X was applied to each section. The sections were then incubated in primary polyclonal rabbit anti-5-HT antiserum (1:1000, 20080, RRID:AB_572263, Immunostar, Hudson, WI, United States) in a blocking solution in a closed moist chamber for $48 \mathrm{~h}$ at $4^{\circ} \mathrm{C}$, followed by incubation in biotinylated anti-rabbit immunoglobulin IgG (1:200) for $30 \mathrm{~min}$ and avidin-biotinylated horseradish peroxidase complex (1:50) for $45 \mathrm{~min}$ at room temperature (PK-6101, RRID:AB_2336820, Vectastain ABC Elite Kit, Vector Laboratories, Burlingame, CA, United States). Antigen-antibody complexes were visualised with Alexa Fluor 488 Streptavidin (1:500; S32354, RRID:AB_2315383, Invitrogen Corporation, Carlsbad, CA, United States). The specificity of the 5 -HT antibody was tested in tilapia brain in a previous study, where an absorption test with 5-HT bovine serum albumin (BSA) conjugate and 5-HT antibody omitted showed negative staining. (Loveland et al., 2014).

\section{Image Analysis}

Section images were captured using a MIRAX MIDI slide scanner (Carl Zeiss, Oberkochen, Germany) with an 
appropriate excitation filter for Alexa Fluor 488 and computer software (Pannoramic Scanner; 3DHISTECH, Budapest, Hungary). Nomenclature for the brain area was adopted from Parhar, 1990, Lillesaar (2011), and Loveland et al. (2014).

\section{Co-localisation of 5-HT Neurons With RNF38 Peptide in the Brain \\ Brain Tissue Preparation for Double-Labelling Immunocytochemistry}

Male tilapia $(n=6)$ were anaesthetised using a $0.02 \%$ benzocaine solution (Sigma, St. Louis, MO, United States). Fish were then decapitated and the brains harvested. Gonads were examined macroscopically to confirm that the fish were sexually matured. The whole brain samples were then fixed in $4 \%$ paraformaldehyde in $0.1 \mathrm{M}$ phosphate buffer $(\mathrm{pH} \mathrm{7.3)}$ for $6 \mathrm{~h}$ at $4{ }^{\circ} \mathrm{C}$ followed by cryoprotection in $20 \%$ sucrose in $0.1 \mathrm{M}$ phosphate buffer ( $\mathrm{pH}$ 7.3). The cryoprotected brain samples were then embedded in frozen section compound (Leica, Wetzlar, Germany) and sectioned coronally at $15 \mu \mathrm{m}$ using a cryostat (Leica CM1860). The coronal sections were divided into two sets and sections that were $30 \mu \mathrm{m}$ apart were used for doublelabelling immunocytochemistry. The sections were mounted onto silane-coated glass slides (Muto Pure Chemicals, Tokyo, Japan) and stored at $-80^{\circ} \mathrm{C}$ until use.

\section{Double-Labelling Immunocytochemistry of 5-HT Neurons With RNF38 Peptide}

Sections were rehydrated in phosphate-buffered saline and a blocking solution containing $2 \%$ normal goat serum and $0.5 \%$ Triton-X was applied to each section. Primary polyclonal rabbit anti-RNF38 antiserum (1:200, ab121487, RRID:AB_11128227, Abcam, Cambridge, United Kingdom) in blocking solution was applied to all sections and the slides were incubated in a closed moist chamber for $48 \mathrm{~h}$ at $4^{\circ} \mathrm{C}$. The sections then were visualised with goat anti-rabbit IgG secondary antibody, Alexa Fluor 594 conjugated (1.400, A11037, RRID:AB_2534095, Thermo Fisher Scientific, Waltham, MA, United States). Then, primary polyclonal rabbit anti-5HT antiserum (1:1000, 20080, RRID:AB_572263, Immunostar, Hudson, WI, United States) in a blocking solution was applied to all sections and the slides were incubated in a closed moist chamber for $48 \mathrm{~h}$ at $4^{\circ} \mathrm{C}$. The sections were then incubated in biotinylated anti-rabbit immunoglobulin $\operatorname{IgG}(1: 200)$ for $30 \mathrm{~min}$ and avidin-biotinylated horseradish peroxidase complex (1:50) for $45 \mathrm{~min}$ at room temperature (PK-6101, RRID:AB_2336820, Vectastain ABC Elite Kit, Vector Laboratories, Burlingame, CA, United States). Antigen-antibody complexes were visualised with Streptavidin, Alexa Fluor 488 conjugate (1:500; S32354, RRID:AB_2315383, Thermo Fisher Scientific, Waltham, MA, United States). The specificity of the RNF38 antibody was tested in the brain of tilapia in a previous study (Cham et al., 2017).

\section{Image Analysis}

Co-localisation of 5-HT neurons and RNF38 peptide was confirmed using the multiphoton and confocal fluorescence microscope (Leica TCS SP8 MP), equipped with Leica Application Suite X software (Leica, Wetzlar, Germany). Laser wavelengths of 488 and $552 \mathrm{~nm}$ were used for the excitation of fluorophores Alexa Fluor 488 and Alexa Fluor 594, respectively. Confocal images for analysis were laser-scanned with an XYZ resolution of $1024 \times 1024$ pixels that covered an area of $177.14 \times 177.14 \mu \mathrm{m}$, using the $\times 25$ objective. The images were collected as Z-stacks with a Z-step size of $0.57 \mu \mathrm{m}$, generating 56 frames. Z-series (frames) of confocal images were then used for $3 \mathrm{D}$ reconstruction. The $3 \mathrm{D}$ image rotation was carefully inspected to confirm expression of RNF38 in the nucleus of 5-HT neurons.

The total number of 5-HT neurons and the percentage of RNF38-positive 5-HT neurons were determined using scanned images of sections captured using a MIRAX MIDI slide scanner (Carl Zeiss, Oberkochen, Germany) with appropriate excitation filters for Alexa Fluor 594 and Alexa Fluor 488, and computer software (Pannoramic Scanner; 3DHISTECH, Budapest, Hungary). The area of interest for each subject was defined as the area between the first and the last sections that contained at least one 5-HT-immunoreactive cell. Cell counting of 5-HT neurons was performed manually based on observation from the scanned sectional images. A 5-HT neuron was counted as positive if the cell bodies with well- defined borders contained detectable green fluorescence labelling and the staining was even throughout the entire cell. The total number of the 5-HT neurons in PPd, PPv, SR and IF was calculated. The diameter of the 5-HT neurons in all 5-HT neuronal populations (PPd, PPv, SR and IF) was determined manually by using this equation: actual diameter $=$ measured diameter on image / magnification. RNF38-immunopositive status within the 5-HT neuron was identified by manual observation from scanned sectional images. Green fluorescent labelled 5-HT neurons were considered RNF38-positive if their nucleus showed detectable red fluorescence immunolabelling and RNF38-negative if they showed no visible nucleus or a nucleus lacking RNF38 immunolabelling. Co-localisation was scored only if RNF38 was present in the nucleus of the 5-HT neurons. The co-localisation percentage of 5-HT neurons and RNF38 in the PPd, PPv, SR and IF with at least one co-localisation were calculated.

\section{RESULTS}

\section{Localisation of 5-HT Neurons in the Brain}

The present study identified the distribution of 5-HT cell bodies in the brains of tilapia (Figures $\mathbf{1} \mathbf{A}-\mathbf{E}_{\mathrm{ii}}$ ). There were three neuronal populations of 5-HT in the tilapia brain; the nucleus of PVO, PP, and the raphe.

The periventricular groups within the posterior hypothalamus collectively constitute the PVO. In the PVO, the 5-HT neurons, with diameters of 5-6 $\mu \mathrm{m}$, were relatively small and densely packed. The majority of the cells in this brain area appeared to have club-like apical dendritic processes extending and protruding into the third ventricle, possibly making contact with the cerebrospinal fluid (CSF) or lying within the ventricular 

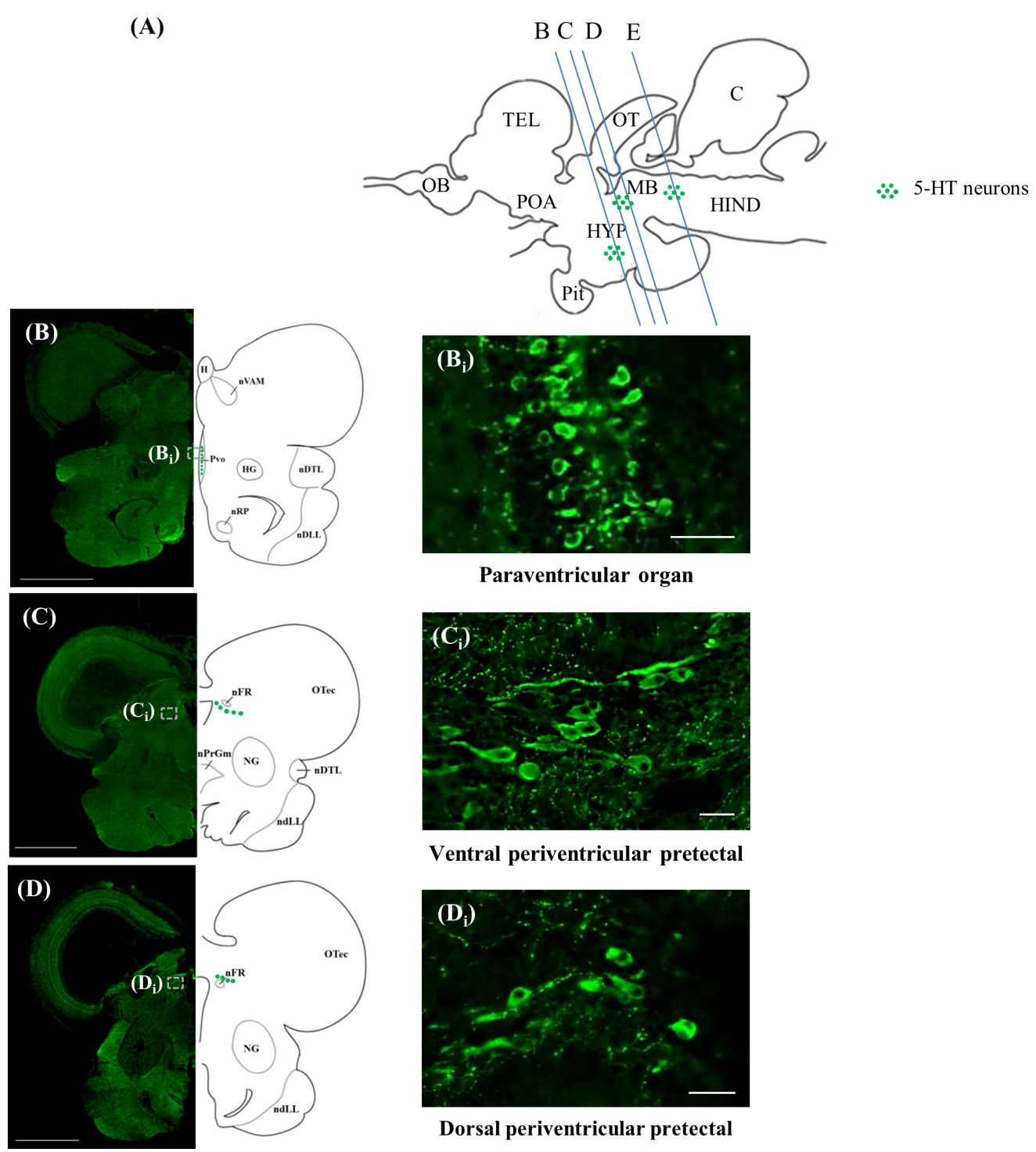

Ventral periventricular pretectal

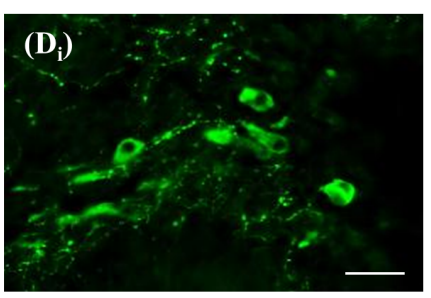

Dorsal periventricular pretectal

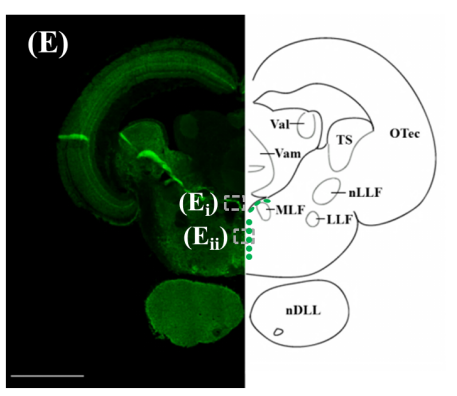

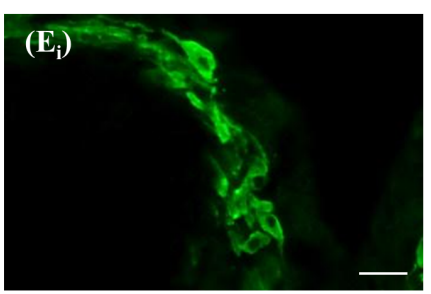

Dorsal raphe

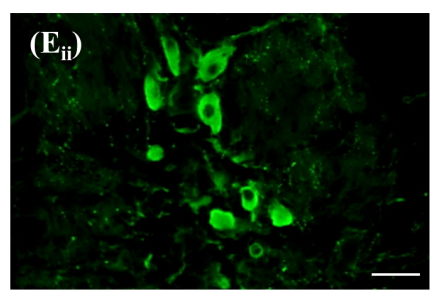

Median raphe

Figure 1

FIGURE 1 | 5-HT-immunoreactive neurons in the brain of tilapia. (A) Schematic sagittal diagram of tilapia brain with approximate locations of coronal sections (B-E) (B-E) Representative low magnification photomicrographs of coronal sections expressing $5-H T$ immunoreactive neurons. Panels $\left(\mathbf{B}_{i}, \mathbf{C}_{\mathbf{i}}, \mathbf{D}_{\mathbf{i}}, \mathbf{E}_{\mathbf{i}}, \mathbf{E}_{\mathbf{i i}}\right)$ show a higher magnification of the boxed area in panels $(\mathbf{B}-\mathbf{E})$, respectively. Scale bars: (B-E) $1000 \mu \mathrm{m} ;\left(\mathbf{B}_{\mathbf{i}}, \mathbf{C}_{\mathbf{i}}, \mathbf{D}_{\mathbf{i}}, \mathbf{E}_{\mathbf{i}}, \mathbf{E}_{\mathbf{i i}}\right) 25 \mu \mathrm{m}$.

wall (Figures $\left.\mathbf{1 B}, \mathbf{B}_{\mathrm{i}}\right)$. There was also a small group of $5-\mathrm{HT}$ neurons (diameter of 5-6 $\mu \mathrm{m}$ ) in the PVO that were globular with short processes and made no contact with the CSF in the third ventricle.
In the PP, the 5-HT neurons were classified into two groups, one situated dorsally of the fasciculus retroflexus (nFR) with another more ventrally. They constitute the dorsal periventricular pretectal nucleus (PPd) and ventral 
periventricular pretectal nucleus $(\mathrm{PPv})$, respectively. In the anterior part of the $\mathrm{PPv}$, the 5-HT cells, with diameters of 5-8 $\mu \mathrm{m}$, were small globular cells clustering together, whereas 5-HT cell bodies in the posterior part of the $\mathrm{PPv}$ were relatively larger (diameter of 8-15 $\mu \mathrm{m}$ ), with axons directed away from the third ventricle (Figures $\mathbf{1 C}, \mathbf{C}_{i}$ ). The majority of these cells in the posterior area of the PPV were either globular or fusiform. In the PPd, the 5-HT cell bodies, with diameters of 8-12 $\mu \mathrm{m}$, were either globular or fusiform (Figures $1 \mathrm{D}, \mathrm{D}_{\mathrm{i}}$ ).

In the raphe, 5-HT neurons were further subdivided into two subpopulations, one situated dorsally between the fasciculi longitudinalis medialis beneath the fourth ventricle and another more ventrally. They constitute the SR and IR, respectively. In the anterior part of the raphe population, the 5-HT neurons (diameter of 8-15 $\mu \mathrm{m}$ ) in the SR were elongated and densely overlapped fusiform cells (Figures $\mathbf{1 E}, \mathbf{E}_{\mathrm{i}}$ ). In more posterior sections, 5-HT neurons (diameter of 8-15 $\mu \mathrm{m})$ in the IR were either globular or fusiform cells arranged in a parallel manner along the medio-sagittal plane (Figures 1E-E $\mathrm{E}_{\mathrm{ii}}$ ).

\section{Total 5-HT Neuronal Number in the Brain}

The 5-HT neuronal number was examined in four subregions of the brain; the PPd, PPV, SR and IR. The PVO population was omitted, as counting was difficult due to the morphology and distribution of the 5-HT neurons, where their cell bodies were small and densely packed together. Furthermore, PVO in teleost fish lacks tph2 gene (Gaspar and Lillesaar, 2012), the key enzyme responsible for the biosynthesis of 5-HT in the brain. In the tilapia brain, the largest population of 5-HT cell bodies was in the raphe of the hindbrain. Male tilapia had an average of $90.4 \pm 7.45-\mathrm{HT}$ neurons in the SR and $284.6 \pm 26.8$ in the IR. In the midbrain, there were an average of $22.3 \pm 3.35$-HT neurons in the PPd and $209.8 \pm 19.7$ of 5 -HT cells in the PPv (Table $\mathbf{1}$ ).

\section{Expression of RNF38 Peptide in 5-HT Neurons}

Double-label immunocytochemistry showed that 5-HT neurons co-localised with RNF38 peptide in all brain areas where 5HT neurons were localised (Figure 2). Midbrain periventricular pretectal had a higher percentage of 5-HT neurons expressing RNF38 peptide $(66.5 \pm 13.7 \%$ in $\mathrm{PPd} ; 77.9 \pm 7.2 \%$ in $\mathrm{PPv})$ than the hindbrain raphe 5 -HT neurons $(35.7 \pm 10.2 \%$ in SR; $49.1 \pm 13.6 \%$ in IR) (Table 1). The PVO population was omitted

TABLE 1 | Total 5-HT neuronal number and percentage of co-localisation of 5-HT neurons with RNF38 peptide in the dorsal periventricular pretectal nucleus, ventral periventricular pretectal nucleus, superior raphe and inferior raphe.

\begin{tabular}{lcc}
\hline Brain area & Neuronal number & $\begin{array}{c}\text { Percentage of } \\
\text { co-localisation (\%) }\end{array}$ \\
\hline Dorsal periventricular pretectal & $22.3 \pm 3.3$ & $66.5 \pm 13.7$ \\
Ventral periventricular pretectal & $209.8 \pm 19.7$ & $77.9 \pm 7.2$ \\
Superior raphe & $90.4 \pm 7.4$ & $35.7 \pm 10.2$ \\
Inferior raphe & $284.6 \pm 26.8$ & $49.1 \pm 13.6$
\end{tabular}

due to reasons mentioned in see Section "Total 5-HT neuronal number in the brain".

\section{DISCUSSION}

\section{Localisation of 5-HT Neurons in the Brain}

The present study examined the distribution of 5-HT neurons in the brain of the Nile tilapia. There were three neuronal populations of 5-HT in the tilapia brain: the nucleus of PVO, $\mathrm{PP}$, and the raphe. The distribution of 5-HT-ir systems observed in the central nervous system of the Nile tilapia is generally in accordance with immunohistochemical studies of other teleost fish (Meek and Joosten, 1989; Batten et al., 1993; Kaslin and Panula, 2001; Loveland et al., 2014).

The present study showed 5-HT neurons in the PVO of the hypothalamus, consistent with studies in non-mammalian vertebrates, such as fish (Kah and Chambolle, 1983; Meek and Joosten, 1989; Kaslin and Panula, 2001; Loveland et al., 2014), amphibians (Sano et al., 1983; Ueda et al., 1984), reptiles (Sano et al., 1983; Ueda et al., 1983) and birds (Challet et al., 1996; Meneghelli et al., 2009). These densely packed 5-HT neurons in the PVO have processes that surround the blood vessels and extend into the third ventricle, suggesting that these cells can detect CSF and blood composition, and possibly secrete substances into the ventricular system and the circulation (Lillesaar, 2011). However, the functions of 5-HT neurons in the PVO remain largely unexplored. As the morphology of the 5HT neurons in the PVO are very similar to the morphology of the CSF-contacting cells, it is possible that these 5-HT neurons are CSF-contacting cells that possess sensory receptors such as mechanoreceptors, chemoreceptors and photoreceptors (Vigh and Vigh-Teichmann, 1998). A recent study in the zebrafish showed that 5-HT in the PVO promotes neurogenesis of 5HT neurons (Pérez et al., 2013), thus suggesting 5-HT is a potent regulator of neurogenesis. Besides, the 5-HT cells in the PVO have been shown to intermingle with dopaminergic and histaminergic cells (Kaslin and Panula, 2001; Filippi et al., 2010); however, the functional relationship between these monoaminergic systems remains to be elucidated. It has been proposed that the 5-HT observed in the PVO may be due to uptake from the third ventricle rather than interneuronal synthesis (Batten et al., 1993).

This study also revealed 5-HT cell bodies in the periventricular pretectal area of the brain. It is interesting to note that 5-HT neurons have been not been identified in the periventricular pretectal area in the brains of mammals, amphibians, reptiles or birds, suggesting that this is a fish-specific feature. Generally, this area is implicated in the modulation of the visuomotor behaviours and integration of multiple sensory modalities with visual input (Wullimann, 1997). In teleost, the optic tectum is densely innervated by 5-HT fibres (Batten et al., 1993; Kaslin and Panula, 2001) although it does not receive innervation from the raphe 5-HT neurons (Lillesaar et al., 2009). Therefore, it is highly possible that the 5-HT neuronal population in the pretectal area is the source of 5-HT innervation to the optic tectum. Therefore, 5$\mathrm{HT}$ in the pretectal area may be involved in the regulation of optic 


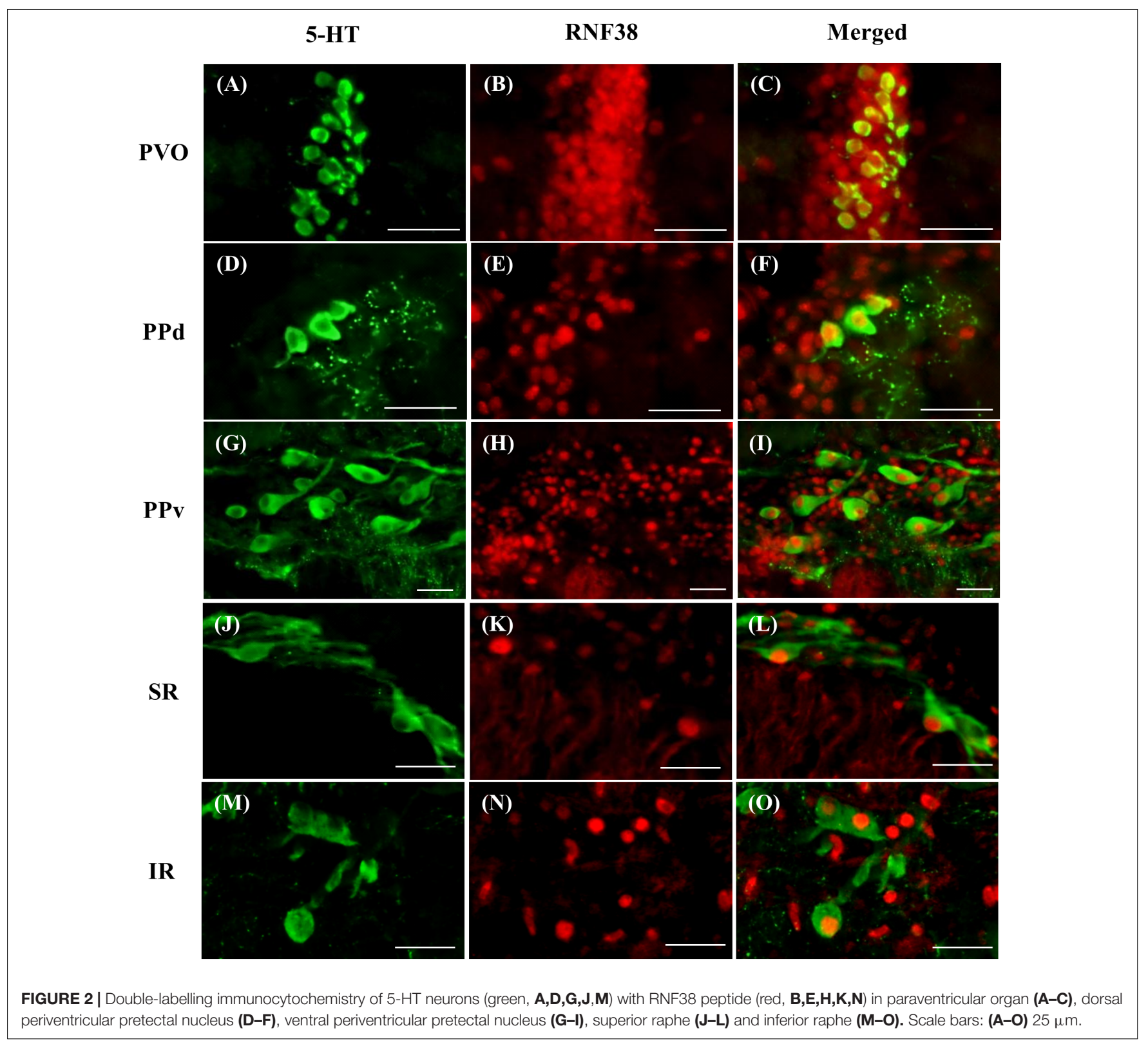

tectum to coordinate the orientation of the eyes, body and tail movements, feeding and escape response, and motor movements (Meek, 1983; Salas et al., 1997; Herrero et al., 1998; Nevin et al., 2010).

The current study showed that the largest population of 5-HT neurons is in the raphe. The raphe 5 -HT population is present in almost all vertebrates, such as mammals (Dahlström and Fuxe, 1964; Steinbusch, 1981; Charnay and Léger, 2010), amphibians (Ueda et al., 1984; Clairambault et al., 1994), reptiles (Wolters et al., 1985; Ayala-Guerrero et al., 1991), birds (Challet et al., 1996) and fish (Meek and Joosten, 1989; Kaslin and Panula, 2001; Loveland et al., 2014), indicating that the 5-HT neuronal population in the raphe is the most well-conserved 5-HT population, thus suggesting an important function in the central nervous system. In mammals, raphe $5-\mathrm{HT}$ is subdivided into nine distinct subpopulations (B1-B9), where each subpopulation corresponds to specific brainstem nuclei (B1, raphe pallidus; $\mathrm{B} 2$, raphe obscurus; $\mathrm{B} 3$, raphe magnus; $\mathrm{B} 4$, dorsal to prepositus hypoglossi; $\mathrm{B} 5$, raphe pontis; $\mathrm{B} 6$, caudal part of raphe dorsalis; B7, raphe dorsalis; B8, centralis; B9, the supralemniscal nucleus) (Steinbusch, 1981; Gaspar and Lillesaar, 2012). However, raphe 5-HT cells in the fish appear to be rather scattered, therefore it is difficult to assign them to neuronal populations homologous to the nine 5-HT subpopulations as identified in mammals. Generally, in fish, raphe 5-HT is classified into SR and IR, where SR 5-HT cells located dorsally between the fasciculi longitudinalis medialis and IR 5-HT cells are located more ventrally. Apart from neuroanotamical locations, 5-HT neurons in the SR and the IR can also be distinguished based on the regions to which they project, electrophysiological properties, molecular architectures 
and functional properties (Kirby et al., 2003; Abrams et al., 2004; Beck et al., 2004; Wylie et al., 2010). Similar to mammals, in the zebrafish, SR provides ascending pathways which innervate most of the brain areas, whereas the IR provides descending pathways to the brain stem and the spinal cord (Lillesaar, 2011). The extensive projections of raphe 5-HT neurons to almost all the brain areas indicate widespread influences of 5HT on behavioural and physiological functions. For example, ascending 5-HT neuronal projections from the raphe to the telencephalon modulates schooling, courtship and sexual and aggressive behaviours (Noble and Borne, 1941; de Bruin, 1980), and to the POA modulates reproduction and sexual behaviour (Verma et al., 1989; Hull et al., 2004). Descending 5-HT neuronal projections from the raphe to the brain stem and spinal cord are important for the mediation of sensory, somatic motor, autonomic and reflex control (Bowker et al., 1983).

\section{5-HT Neurons Express RNF38 Peptide}

5-HT modulates diverse behavioural and physiological functions such as mood, fear, aggression, appetite, sleep, memory and reproduction (Jacobs and Azmitia, 1992; Lucki, 1998; Charnay and Léger, 2010; Lillesaar, 2011). 5-HT has also been shown to regulate developmental processes such as cell migration, cell proliferation, neuronal differentiation, neurogenesis, synaptogenesis and apoptosis (Azmitia, 2001; Gaspar et al., 2003; Cote et al., 2007; Pérez et al., 2013). The presence of RNF38 in 5-HT neurons suggests that RNF38 might be involved in the regulation of these behavioural, physiological and developmental functions by modulating the 5-HT system.

To date, the functions of RNF38 remain unclear. A recent study has shown that RNF38 exhibits E2-dependent E3 ubiquitin ligase activity (Sheren and Kassenbrock, 2013; Buetow et al., 2015), indicating that RNF38 is involved in the ubiquitin proteosome system (UPS), which governs protein homeostasis within neurons by the continuous degradation of intracellular proteins by proteosomes. Several E3 ubiquitin ligases have been shown to regulate neuronal properties such as neurogenesis (Tuoc and Stoykova, 2008; Westbrook et al., 2008), neuronal growth and development (Tursun et al., 2005), synaptogenesis (DiAntonio et al., 2001) and synaptic plasticity (van Roessel et al., 2004) via the UPS. Therefore, as an E3 ubiquitin ligase, RNF38 may play a critical role in maintaining neuronal structures or regulating neuronal functions of the 5-HT system via the UPS.

A similar E3 ubiquitin ligase RINES/RNF180 has shown prominent functions in the modulation of the 5-HT system. RINES/RNF180 mediates ubiquitination of monoamine oxidase (MAO-A), a 5-HT-metabolising enzyme which plays a critical role in emotional and social behaviour (Cases et al., 1995; Deckert et al., 1999; Schulze et al., 2000; Bortolato et al., 2011). A recent study has shown that serotonin transporter (SERT) protein, a

\section{REFERENCES}

Abrams, J. K., Johnson, P. L., Hollis, J. H., and Lowry, C. A. (2004). Anatomic and functional topography of the dorsal raphe nucleus. Ann. N. Y. Acad. Sci. 1018, 46-57. doi: 10.1196/annals. 1296.005 carrier protein, is ubiquitinated and degraded by proteasome (Mouri et al., 2016), but the ubiquitin ligase responsible for the ubiquitination of SERT protein remains unknown. Although E3 ubiquitin ligase confers substrate specificity, each individual E3 ubiquitin ligase is capable of recruiting more than one substrate and, similarly, the same substrate may be targeted by more than one E3 ubiquitin ligase (Nishitani et al., 2006; Stegmüller and Bonni, 2010). Thus, it is plausible that RNF38 can regulate 5HT neuronal activity by targeting 5-HT-associated molecules such as MAO-A and SERT for ubiquitin-mediated degradation by proteasomes; this represents a possibility that needs to be investigated.

Since the deregulation of UPS is suggested to be involved in social behaviour and neurological disorders such as depression, the identification of RNF38 ubiquitin ligase pathways that control the 5-HT system could advance our understanding in these neurological disorders.

\section{CONCLUSION}

In summary, we have identified the localisation of three 5-HT neuronal populations in the brain of tilapia; PVO, PP, and raphe. To our knowledge, this is the first evidence that RNF38 peptide is expressed in the nucleus of 5-HT neurons, suggesting that RNF38 may interact with cellular proteins and modulate cellular functions in different 5 -HT neuronal populations.

\section{AUTHOR CONTRIBUTIONS}

KC conducted all the research experiments. TS confirmed all the data. IP and TS designed the experiments and edited the manuscript.

\section{FUNDING}

This work was supported by research grants from Monash University Malaysia and Fundamental Research Grant Scheme (FRGS/2/2014/STO3/MUSM/02/01) from the Ministry of Higher Education, Malaysia.

\section{ACKNOWLEDGMENTS}

We thank the Drug and Discovery Platform and Bioimaging Platform in BRIMS, the Jeffrey Cheah School of Medicine and the Health Science for providing the facilities. We also thank Ms Raeesah Sabeen (Research Scholar Program).

Ayala-Guerrero, F., Huitrón-Reséndiz, S., and Mancilla, R. (1991) Characterization of the raphe nuclei of the reptile Ctenosaura pectinata. Physiol. Behav. 50, 717-722. doi: 10.1016/0031-9384(91)90008-C

Azmitia, E. C. (2001). Modern views on an ancient chemical: serotonin effects on cell proliferation, maturation, and apoptosis. Brain Res. Bull. 56, 413-424. doi: 10.1016/S0361-9230(01)00614-1 
Batten, T., Berry, P., Maqbool, A., Moons, L., and Vandesande, F. (1993). Immunolocalization of catecholamine enzymes, serotonin, dopamine and L-dopa in the brain o/. f Dicentrarchus labrax (teleostei). Brain Res. Bull. 31, 233-252. doi: 10.1016/0361-9230(93)90214-V

Beck, S. G., Pan, Y.-Z., Akanwa, A. C., and Kirby, L. G. (2004). Median and dorsal raphe neurons are not electrophysiologically identical. J. Neurophysiol. 91, 994-1005. doi: 10.1152/jn.00744.2003

Bortolato, M., Chen, K., Godar, S. C., Chen, G., Wu, W., Rebrin, I., et al. (2011). Social deficits and perseverative behaviors, but not overt aggression, in MAOA hypomorphic mice. Neuropsychopharmacology 36, 2674-2688. doi: 10.1038/ npp. 2011.157

Bowker, R., Westlund, K., Sullivan, M., Wilber, J., and Coulter, J. (1983). Descending serotonergic, peptidergic and cholinergic pathways from the raphe nuclei: a multiple transmitter complex. Brain Res. 288, 33-48. doi: 10.1016/ 0006-8993(83)90079-3

Breier, A. (1995). Serotonin, schizophrenia and antipsychotic drug action. Schizophr. Res. 14, 187-202. doi: 10.1016/0920-9964(94)00043-8

Buetow, L., Gabrielsen, M., Anthony, N. G., Dou, H., Patel, A., Aitkenhead, H., et al. (2015). Activation of a primed RING E3-E2-ubiquitin complex by non-covalent ubiquitin. Mol. Cell. 58, 297-310. doi: 10.1016/j.molcel.2015.02.017

Cases, O., Seif, I., Grimsby, J., Gaspar, P., Chen, K., Pournin, S., et al. (1995). Aggressive behavior and altered amounts of brain serotonin and norepinephrine in mice lacking MAOA. Science 268, 1763-1766. doi: 10.1126/ science.7792602

Challet, E., Miceli, D., Pierre, J., Repérant, J., Masicotte, G., Herbin, M., et al. (1996). Distribution of serotonin-immunoreactivity in the brain of the pigeon (Columba livia). Anat. Embryol. 193, 209-227. doi: 10.1007/BF00198325

Cham, K. L., Soga, T., and Parhar, I. S. (2017). RING finger protein 38 Is a neuronal protein in the brain of Nile Tilapia, Oreochromis niloticus. Front. Neuroanat. 11:72. doi: 10.3389/fnana.2017.00072

Charnay, Y., and Léger, L. (2010). Brain serotonergic circuitries. Dialog. Clin. Neurosci. 12, 471-487.

Charney, D. S., Woods, S. W., Goodman, W. K., and Heninger, G. (1987). Serotonin function in anxiety. Psychopharmacology 92, 14-24. doi: 10.1007/BF00215473

Clairambault, P., Christophe, N., Pairault, C., Herbin, M., Ward, R., and Reperant, J. (1994). Organization of the serotoninergic system in the brain of two amphibian species, Ambystoma mexicanum (Urodela) and Typhlonectes compressicauda (Gymnophiona). Anat. Embryol. 190, 87-99. doi: 10.1007/ BF00185849

Cote, F., Fligny, C., Bayard, E., Launay, J.-M., Gershon, M. D., Mallet, J., et al. (2007). Maternal serotonin is crucial for murine embryonic development. Proc. Natl. Acad. Sci. U.S.A. 104, 329-334. doi: 10.1073/pnas.0606722104

Dahlström, A., and Fuxe, K. (1964). Localization of monoamines in the lower brain stem. Cell. Mol. Life Sci. 20, 398-399. doi: 10.1007/BF02147990

de Bruin, J. P. (1980). “Telencephalon and behavior in teleost fish," in Comparative Neurology of the Telencephalon, ed. S. O. Ebbesson (Berlin: Springer Science \& Business Media), 175-201. doi: 10.1007/978-1-4613-2988-6_7

Deckert, J., Catalano, M., Syagailo, Y. V., Bosi, M., Okladnova, O., Di Bella, D., et al. (1999). Excess of high activity monoamine oxidase A gene promoter alleles in female patients with panic disorder. Hum. Mol. Genet. 8, 621-624. doi: $10.1093 / \mathrm{hmg} / 8.4 .621$

DiAntonio, A., Haghighi, A. P., Portman, S. L., Lee, J. D., Amaranto, A. M., and Goodman, C. S. (2001). Ubiquitination-dependent mechanisms regulate synaptic growth and function. Nature 412, 449-452. doi: 10.1038/35086595

Eisenberg, I., Hochner, H., Levi, T., Yelin, R., Kahan, T., and MitraniRosenbaum, S. (2002). Cloning and characterization of a novel human gene RNF38 encoding a conserved putative protein with a RING finger domain. Biochem. Biophys. Res. Commun. 294, 1169-1176. doi: 10.1016/S0006-291X(02) 00584-3

Filippi, A., Mahler, J., Schweitzer, J., and Driever, W. (2010). Expression of the paralogous tyrosine hydroxylase encoding genes th1 and th 2 reveals the full complement of dopaminergic and noradrenergic neurons in zebrafish larval and juvenile brain. J. Comp. Neurol. 518, 423-438. doi: 10.1002/cne. 22213

Fu, C., Hickey, M., Morrison, M., McCarter, R., and Han, E.-S. (2006). Tissue specific and non-specific changes in gene expression by aging and by early stage CR. Mech. Ageing Dev. 127, 905-916. doi: 10.1016/j.mad.2006.09.006
Gaspar, P., Cases, O., and Maroteaux, L. (2003). The developmental role of serotonin: news from mouse molecular genetics. Nat. Rev. Neurosci. 4, 10021012. doi: $10.1038 /$ nrn 1256

Gaspar, P., and Lillesaar, C. (2012). Probing the diversity of serotonin neurons. Phil. Trans. R. Soc. B 367, 2382-2394. doi: 10.1098/rstb.2011.0378

Gmachl, M., Gieffers, C., Podtelejnikov, A. V., Mann, M., and Peters, J. M. (2000). The RING-H2 finger protein APC11 and the E2 enzyme UBC4 are sufficient to ubiquitinate substrates of the anaphase-promoting complex. Proc. Natl. Acad. Sci. U.S.A. 97, 8973-8978. doi: 10.1073/pnas.97.16.8973

Gowen, L. C., Avrutskaya, A. V., Latour, A. M., Koller, B. H., and Leadon, S. A. (1998). BRCA1 required for transcription-coupled repair of oxidative DNA damage. Science 281, 1009-1012. doi: 10.1126/science.281.5379.1009

Herrero, L., Rodríguez, F., Salas, C., and Torres, B. (1998). Tail and eye movements evoked by electrical microstimulation of the optic tectum in goldfish. Exp. Brain Res. 120, 291-305. doi: 10.1007/s002210050403

$\mathrm{Hu}, \mathrm{S}$., and Yang, X. (2003). Cellular inhibitor of apoptosis 1 and 2 are ubiquitin ligases for the apoptosis inducer Smac/DIABLO. J. Biol. Chem. 278, 1005510060. doi: 10.1074/jbc.M207197200

Hull, E. M., Muschamp, J. W., and Sato, S. (2004). Dopamine and serotonin: influences on male sexual behavior. Physiol. Behav. 83, 291-307. doi: 10.1016/j. physbeh.2004.08.018

Jacobs, B. L., and Azmitia, E. C. (1992). Structure and function of the brain serotonin system. Physiol. Rev. 72, 165-229. doi: 10.1152/physrev.1992.72.1.165

Jia, L., Soengas, M. S., and Sun, Y. (2009). ROC1/RBX1 E3 ubiquitin ligase silencing suppresses tumor cell growth via sequential induction of G2-M arrest, apoptosis, and senescence. Cancer Res. 69, 4974-4982. doi: 10.1158/0008-5472. CAN-08-4671

Kah, O., and Chambolle, P. (1983). Serotonin in the brain of the goldfish, Carassius auratus. Cell Tissue Res. 234, 319-333. doi: 10.1007/BF00213771

Kaslin, J., and Panula, P. (2001). Comparative anatomy of the histaminergic and other aminergic systems in zebrafish (Danio rerio). J. Comp. Neurol. 440, 342-377. doi: 10.1002/cne.1390

Kirby, L., Pernar, L., Valentino, R., and Beck, S. (2003). Distinguishing characteristics of serotonin and non-serotonin-containing cells in the dorsal raphe nucleus: electrophysiological and immunohistochemical studies. Neuroscience 116, 669-683. doi: 10.1016/S0306-4522(02)00584-5

Kojima, K., Konopleva, M., Samudio, I. J., Shikami, M., Cabreira-Hansen, M., McQueen, T., et al. (2005). MDM2 antagonists induce p53-dependent apoptosis in AML: implications for leukemia therapy. Blood 106, 3150-3159. doi: 10.1182/ blood-2005-02-0553

Lillesaar, C. (2011). The serotonergic system in fish. J. Chem. Neuroanat. 41, 294-308. doi: 10.1016/j.jchemneu.2011.05.009

Lillesaar, C., Stigloher, C., Tannhäuser, B., Wullimann, M. F., and Bally-Cuif, L. (2009). Axonal projections originating from raphe serotonergic neurons in the developing and adult zebrafish, Danio rerio, using transgenics to visualize raphe-specific pet1 expression. J. Comp. Neurol. 512, 158-182. doi: 10.1002/cne. 21887

Loveland, J. L., Uy, N., Maruska, K. P., Carpenter, R. E., and Fernald, R. D. (2014). Social status differences regulate the serotonergic system of a cichlid fish, Astatotilapia burtoni. J. Exp. Biol. 217, 2680-2690. doi: 10.1242/jeb.100685

Lucki, I. (1998). The spectrum of behaviors influenced by serotonin. Biol. Psychiatry 44, 151-162. doi: 10.1016/S0006-3223(98)00139-5

Matsuda, N., Suzuki, T., Tanaka, K., and Nakano, A. (2001). Rma1, a novel type of RING finger protein conserved from Arabidopsis to human, is a membranebound ubiquitin ligase. J. Cell Sci. 114, 1949-1957.

Meek, J. (1983). Functional anatomy of the tectum mesencephali of the goldfish. An explorative analysis of the functional implications of the laminar structural organization of the tectum. Brain Res. Rev. 6, 247-297. doi: 10.1016/01650173(83)90008-5

Meek, J., and Joosten, H. (1989). Distribution of serotonin in the brain of the mormyrid teleost Gnathonemus petersii. J. Comp. Neurol. 281, 206-224. doi: 10.1002/cne.902810205

Meneghelli, C., Rocha, N. H., Mengatto, V., Hoeller, A. A., Santos, T. S., Lino-de-Oliveira, C., et al. (2009). Distribution of tryptophan hydroxylaseimmunoreactive neurons in the brainstem and diencephalon of the pigeon (Columba livia). J. Chem. Neuroanat. 38, 34-46. doi: 10.1016/j.jchemneu.2009. 03.007 
Moriya, S., Khel, N. B., and Parhar, I. S. (2015). Cloning and serotonergic regulation of RING finger protein38 ( $\mathrm{rnf} 38$ ) in the brain of medaka (Oryzias latipes). Neuroscience 294, 109-115. doi: 10.1016/j.neuroscience.2015.03.012

Mouri, A., Ikeda, M., Koseki, T., Iwata, N., and Nabeshima, T. (2016). The ubiquitination of serotonin transporter in lymphoblasts derived from fluvoxamine-resistant depression patients. Neurosci. Lett. 617, 22-26. doi: 10. 1016/j.neulet.2016.01.064

Nacheva, E. P., Brazma, D., Virgili, A., Howard-Reeves, J., Chanalaris, A., Gancheva, K., et al. (2010). Deletions of immunoglobulin heavy chain and $\mathrm{T}$ cell receptor gene regions are uniquely associated with lymphoid blast transformation of chronic myeloid leukemia. BMC Genomics 11:41. doi: 10. 1186/1471-2164-11-41

Nevin, L. M., Robles, E., Baier, H., and Scott, E. K. (2010). Focusing on optic tectum circuitry through the lens of genetics. BMC Biol. 8:126. doi: 10.1186/1741-70078-126

Nishitani, H., Sugimoto, N., Roukos, V., Nakanishi, Y., Saijo, M., Obuse, C., et al. (2006). Two E3 ubiquitin ligases, SCF-Skp2 and DDB1-Cul4, target human Cdt1 for proteolysis. EMBO J. 25, 1126-1136. doi: 10.1038/sj.emboj.7601002

Noble, G., and Borne, R. (1941). The effect of forebrain lesions on the sexual and fighting behavior of Betta splendens and other fishes. Anat. Rec. 79:49.

Owens, M. J., and Nemeroff, C. B. (1994). Role of serotonin in the pathophysiology of depression: focus on the serotonin transporter. Clin. Chem. 40, 288-295.

Parhar, I. S. (1990). Neuroendocrinology of Oreochromis mossambicus. Ph.D. thesis, Natinoal University of Singapore, Singapore, 1, 1-265.

Pérez, M. R., Pellegrini, E., Cano-Nicolau, J., Gueguen, M. M., Guillou, M. L., Merot, Y., et al. (2013). Relationships between radial glial progenitors and 5HT neurons in the paraventricular organ of adult zebrafish-potential effects of serotonin on adult neurogenesis. Eur. J. Neurosci. 38, 3292-3301. doi: 10.1111/ ejn. 12348

Roperch, J.-P., Lethrone, F., Prieur, S., Piouffre, L., Israeli, D., Tuynder, M., et al. (1999). SIAH-1 promotes apoptosis and tumor suppression through a network involving the regulation of protein folding, unfolding, and trafficking: identification of common effectors with $\mathrm{p} 53$ and p21Waf1. Proc. Natl. Acad. Sci. U.S.A. 96, 8070-8073. doi: 10.1073/pnas.96.14.8070

Salas, C., Herrero, L., Rodriguez, F., and Torres, B. (1997). Tectal codification of eye movements in goldfish studied by electrical microstimulation. Neuroscience 78, 271-288. doi: 10.1016/S0306-4522(97)83048-5

Sanada, M., Suzuki, T., Shih, L.-Y., Otsu, M., Kato, M., Yamazaki, S., et al. (2009). Gain-of-function of mutated C-CBL tumour suppressor in myeloid neoplasms. Nature 460, 904-908. doi: 10.1038/nature08240

Sano, Y., Ueda, S., Yamada, H., Takeuchi, Y., Goto, M., and Kawata, M. (1983). Immunohistochemical demonstration of serotonin-containing CSF-contacting neurons in the submammalian paraventricular organ. Histochemistry $77,423-$ 430. doi: $10.1007 / \mathrm{BF} 00495798$

Sato, T., Tran, T. H., Peck, A. R., Liu, C., Ertel, A., Lin, J., et al. (2013). Global profiling of prolactin-modulated transcripts in breast cancer in vivo. Mol. Cancer 12:59. doi: 10.1186/1476-4598-12-59

Schulze, T. G., Müller, D. J., Krauss, H., Scherk, H., Ohlraun, S., Syagailo, Y. V., et al. (2000). Association between a functional polymorphism in the monoamine oxidase A gene promoter and major depressive disorder. Am. J. Med. Genet. 96, 801-803. doi: 10.1002/1096-8628(20001204)96:6<801::AID-AJMG21> 3.0.CO;2-4

Sheren, J. E., and Kassenbrock, C. K. (2013). RNF38 encodes a nuclear ubiquitin protein ligase that modifies p53. Biochem. Biophys. Res. Commun. 440, 473-478. doi: 10.1016/j.bbrc.2013.08.031

Srivastava, A., Woolford, C. A., and Jones, E. W. (2000). Pep3p/Pep5p complex: a putative docking factor at multiple steps of vesicular transport to the vacuole of Saccharomyces cerevisiae. Genetics 156, 105-122.

Stegmüller, J., and Bonni, A. (2010). Destroy to create: E3 ubiquitin ligases in neurogenesis. F1000 Biol. Rep. 2:38. doi: 10.3410/B2-38
Steinbusch, H. W. M. (1981). Distribution of serotonin-immunoreactivity in the central nervous system of the rat-cell bodies and terminals. Neuroscience 6, 557-618. doi: 10.1016/0306-4522(81)90146-9

Tuoc, T. C., and Stoykova, A. (2008). Trim 11 modulates the function of neurogenic transcription factor Pax6 through ubiquitin-proteosome system. Genes Dev. 22, 1972-1986. doi: 10.1101/gad.471708

Tursun, B., Schlüter, A., Peters, M. A., Viehweger, B., Ostendorff, H. P., Soosairajah, J., et al. (2005). The ubiquitin ligase Rnf6 regulates local LIM kinase 1 levels in axonal growth cones. Genes Dev. 19, 2307-2319. doi: 10.1101/gad. 1340605

Ueda, S., Nojyo, Y., and Sano, Y. (1984). Immunohistochemical demonstration of the serotonin neuron system in the central nervous system of the bullfrog, Rana catesbeiana. Anat. Embryol. 169, 219-229. doi: 10.1007/BF00315627

Ueda, S., Takeuchi, Y., and Sano, Y. (1983). Immunohistochemical demonstration of serotonin neurons in the central nervous system of the turtle (Clemmys japonica). Anat. Embryol. 168, 1-19. doi: 10.1007/BF00305395

Ulrich, H. D., and Jentsch, S. (2000). Two RING finger proteins mediate cooperation between ubiquitin-conjugating enzymes in DNA repair. EMBO J. 19, 3388-3397. doi: 10.1093/emboj/19.13.3388

Vallabhapurapu, S., Matsuzawa, A., Zhang, W., Tseng, P.-H., Keats, J. J., Wang, H., et al. (2008). Nonredundant and complementary functions of TRAF2 and TRAF3 in a ubiquitination cascade that activates NIK-dependent alternative NF-KB signaling. Nat. Immunol. 9, 1364-1370. doi: 10.1038/ni.1678

van Roessel, P., Elliott, D. A., Robinson, I. M., Prokop, A., and Brand, A. H. (2004). Independent regulation of synaptic size and activity by the anaphase-promoting complex. Cell 119, 707-718. doi: 10.1016/j.cell.2004.11.028

Verma, S., Chhina, G. S., Kumar, V. M., and Singh, B. (1989). Inhibition of male sexual behavior by serotonin application in the medial preoptic area. Physiol. Behav. 46, 327-332. doi: 10.1016/0031-9384(89)90275-8

Vigh, B., and Vigh-Teichmann, I. (1998). Actual problems of the cerebrospinal fluid-contacting neurons. Microsc. Res. Tech. 41, 57-83. doi: 10.1002/(SICI) 1097-0029(19980401)41:1<57::AID-JEMT6>3.0.CO;2-R

Westbrook, T. F., Hu, G., Ang, X. L., Mulligan, P., Pavlova, N. N., Liang, A., et al. (2008). SCF $\beta$-TRCP controls oncogenic transformation and neural differentiation through REST degradation. Nature 452, 370-374. doi: 10.1038/ nature 06780

Wolters, J., Ten Donkelaar, H., Steinbusch, H., and Verhofstad, A. (1985). Distribution of serotonin in the brain stem and spinal cord of the lizard Varanus exanthematicus: an immunohistochemical study. Neuroscience 14, 169-193. doi: 10.1016/0306-4522(85)90172-1

Wullimann, M. F. (1997). “The central nervous system," in The Physiology of Fishes, eds D. H. Evans and J. B. Claiborne (Boca Raton, FL: CRC Press), 245-282.

Wylie, C. J., Hendricks, T. J., Zhang, B., Wang, L., Lu, P., Leahy, P., et al. (2010). Distinct transcriptomes define rostral and caudal serotonin neurons. J. Neurosci. 30, 670-684. doi: 10.1523/JNEUROSCI.465609.2010

Xiong, D., Zhu, S.-Q., Wu, Y.-B., Jin, C., Jiang, J.-H., Liao, Y.-F., et al. (2018). Ring finger protein 38 promote non-small cell lung cancer progression by endowing cell EMT phenotype. J. Cancer 9, 841-850. doi: 10.7150/jca. 23138

Conflict of Interest Statement: The authors declare that the research was conducted in the absence of any commercial or financial relationships that could be construed as a potential conflict of interest.

Copyright $\odot 2018$ Cham, Soga and Parhar. This is an open-access article distributed under the terms of the Creative Commons Attribution License (CC BY). The use, distribution or reproduction in other forums is permitted, provided the original author(s) and the copyright owner(s) are credited and that the original publication in this journal is cited, in accordance with accepted academic practice. No use, distribution or reproduction is permitted which does not comply with these terms. 